\title{
Caracterização Famacobotânica das Folhas de Eugenia Uniflora L. (Myrtaceae) Coletadas em Anápolis - GO, Brasil
}

Paulo I. D. Assunção, José R. de Paula \& Joelma A. M. de Paula

Eugenia uniflora L. (Myrtaceae), conhecida como pitangueira, é uma das 14 espécies do gênero, amplamente distribuídas na América do Sul. Este trabalho visou verificar a autenticidade das folhas de E. uniflora coletadas em Anápolis, GO. A caracterização macroscópica foi feita à vista desarmada. Para o estudo microscópico, foram realizadas secções transversais e paradérmicas, seguido da fixação e coloração. Os principais dados encontrados para diagnose foram: estômatos ao mesmo nível das células da epiderme, ausência de tricomas, ausência de hipoderme e presença de cristais do tipo drusas e organizados em série. Os dados mostram conformidade com a Farmacopeia Brasileira $5^{\circ}$ edição.

Palavras-chave: Morfoanatomia; Pitangueira; Estudo farmacognóstico.

Eugenia uniflora L. (Myrtaceae), also known as pitangueira, is one of 14 species of the genus widely distributed in South America. This study aimed to verify the authenticity of E. uniflora leaves collected in Anapolis, GO. Macroscopic characterization was done with naked eye. For the microscopic study were carried out cross sections and paradermic sections, followed by fixation and staining. The main data for diagnosis were; stomata at the same level of epidermal cells, absence of trichomes, no hypodermis and arrangement of druze crystals in series. The data show compliance with the Brazilian Pharmacopoeia 5th edition.

Keywords: Morphoanatomy; Pitangueira; Pharmacognostic study. 


\section{Introdução}

Eugenia uniflora L., popularmente conhecida como pitangueira, é membro da família Myrtaceae, composta por mais de 100 gêneros e 3000 espécies. Ela é uma das 14 espécies do gênero amplamente distribuída na região subtropical norte e nordeste da Argentina, Brasil, Uruguai e Paraguai ${ }^{1}$. A árvore tem sido introduzida em outros continentes, apesar de ser nativa do Brasil e com distribuição, desde o Planalto Meridional até as restingas litorâneas do Nordeste até o Sul². A infusão das folhas é usada na medicina popular como adstringente, antidiarreico, carminativo, diurético, antireumático, antifebril, hipotensor, redutor do colesterol sanguíneo e controlador de ácido úrico na urina ${ }^{3}$.

Schapoval et al. ${ }^{4}$ estudando infusos e decoctos obtidos a partir de folhas frescas de E. uniflora comprovaram seu efeito anti-inflamatório e analgésico. Consolini et al. ${ }^{5}$ demonstraram a atividade antihipertensiva do extrato bruto das folhas em ratos normotensos. Momose et al. ${ }^{6}$ atribuíram atividade inibitória ao extrato bruto das folhas de E. uniflora sobre as enzimas $\alpha$-glicosidase, maltase e sucrase, sendo, por isso, útil no tratamento de diabetes. Considerando a importância medicinal de Eugenia uniflora e visando contribuir com o conhecimento farmacobotânico de espécies da flora brasileira, por meio de parâmetros para testes de autenticidade, este trabalho foi elaborado com o objetivo de realizar o estudo morfoanatômico das folhas adultas de Eugenia uniflora coletadas na cidade de Anápolis, Goiás.

\section{Materiais e Métodos}

O material botânico constituído de folhas de Eugenia uniflora $L$. foi coletado no município de Anápolis, Goiás (16 $17^{\circ} 13,8^{\prime \prime} \mathrm{S}$ e $48^{\circ} 57^{\prime}$ 22,7' W) no período de julho a agosto de 2014. Foram utilizadas folhas adultas completamente expandidas, coletadas abaixo do terceiro nó. O material foi identificado pela Profa. Dra. Mirley Luciene dos Santos da Universidade Estadual de Goiás (UEG), e as exsicatas foram depositadas no herbário desta universidade, sob registro HUEG2090.

A caracterização macroscópica das folhas foi feita à vista desarmada e por meio de observação, segundo parâmetros descritos por Oliveira, Akisue, Akisue ${ }^{7}$ e Oliveira e Akisue ${ }^{8}$.

Para o estudo anatômico das folhas, foram utilizados fragmentos de nervura principal, região de internervura, bordo e pecíolo. Para isso, as amostras foram fixadas em FPA [formaldeído a 37\%, ácido propiônico e etanol a $70 \%$ na proporção de 1:1:18 - (V/V)] por um período de 24 horas e posteriormente conservadas em etanol $70 \%(\mathrm{~V} / \mathrm{V})$. Foram realizadas secções transversais à mão livre dos fragmentos fixados e cortes paradérmicos das faces adaxial e abaxial de folhas frescas. Os cortes foram submetidos ao processo de dupla coloração com azul de Alcian/safranina 9:19. As lâminas foram confeccionadas utilizando solução de glicerina 1:1. O registro fotográfico das estruturas anatômicas foi realizado em fotomicroscópio (ZEISS-AXIOSKOP).

\section{Resultados e Discussão}

O espécime é uma arvoreta com aproximadamente 4 metros de altura (Figura 1A), tronco liso e cilíndrico cinza amarelado (Figura 1B), com folhas simples e opostas. Durante o período de coleta das folhas, não foi possível observar flores ou frutos. De acordo com Lorenzi e Matos, ${ }^{2}$ a espécie E. uniflora é arbustiva ou árvore semidecídua, variando entre 4 e $10 \mathrm{~m}$ de altura. No Cerrado brasileiro, pode ocorrer a espécie Eugenia pitanga, que apresenta porte arbustivo inferior a $1 \mathrm{~m}$ de altura, porém, as demais características morfológicas são idênticas a E. uniflora. As flores são de cor branca, solitárias ou em grupos de 2 a 3 nas axilas e nas extremidades dos ramos. Os rizomas tem propriedade de rebrotar sob a árvore, produzindo touceiras ${ }^{2}$.

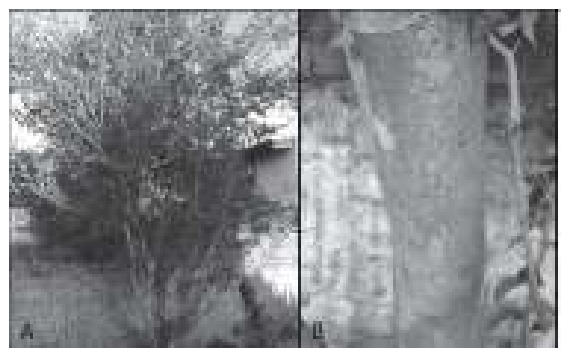

Figura 1. E. uniflora em seu local de coleta na cidade de Anápolis, Goiás. Aspecto geral da planta (A) e detalhe do tronco da planta (B). 
As folhas apresentam entre 2 a $4 \mathrm{~cm}$ de largura e cerca de 4 a $7 \mathrm{~cm}$ de comprimento (Figura 2). O contorno foliar é lanceolado e ovado, base obtusa, são curtamente pecioladas, o pecíolo é achatado (aproximadamente 0,1 a $0,2 \mathrm{~cm}$ ). $\mathrm{O}$ ápice foliar é acuminado e alguns são cuspidados, a margem é inteira e levemente sinuosa. A superfície foliar é glabra e a nervura principal é proeminente na face abaxial. Esses dados estão em conformidade com outros estudos ${ }^{2,10,11,12}$. Alves et al. ${ }^{12}$ demonstraram que pode ocorrer variação no tamanho do limbo foliar de E. uniflora, em função do ambiente de coleta (urbano ou rural) levando em conta a poluição como fator de interferência no desenvolvimento do vegetal.

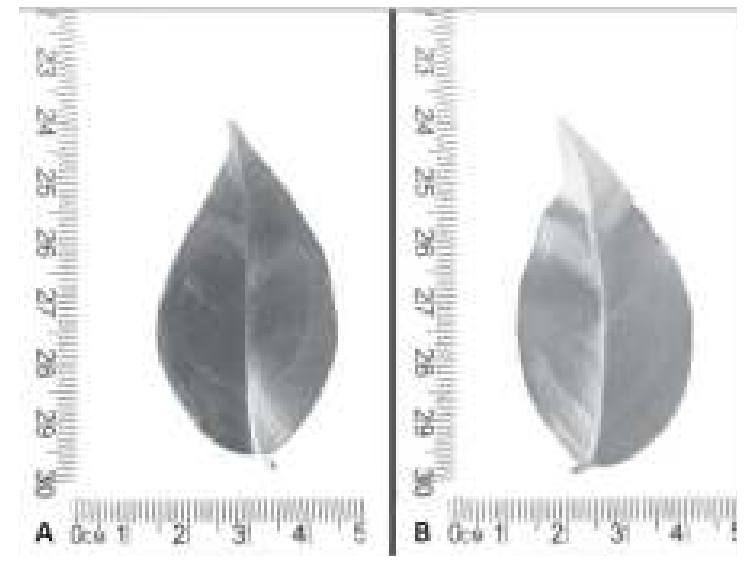

Figura 2. Folhas de E. uniflora em vista frontal. Face adaxial (A) e abaxial (B).

Quanto à anatomia foliar, em vista frontal, a epiderme de ambas as faces apresenta células de dimensões variadas (Figura 3) com paredes anticlinais levemente espessadas. Em ambas as faces, é possível observar a sinuosidade das paredes celulares, entretanto, isso se torna mais evidente na superfície abaxial. Foram evidenciados pares de células que acompanham as estruturas secretoras, estas, por sua vez, apresentam conteúdo típico para cada espécie pertencente à família Myrtaceae, sendo constituído por óleo essencial ${ }^{13}$. Somente na face abaxial (Figura 3B e C) foram evidenciados estômatos paracíticos (folhas hipoestomáticas), esta característica é considerada comum para as plantas terrestres onde a temperatura é mais elevada na face abaxial ${ }^{14}$. A ausência de tricomas já foi apontada anteriormente como um fator de diagnóstico na espécie E. uniflora ${ }^{15}$.

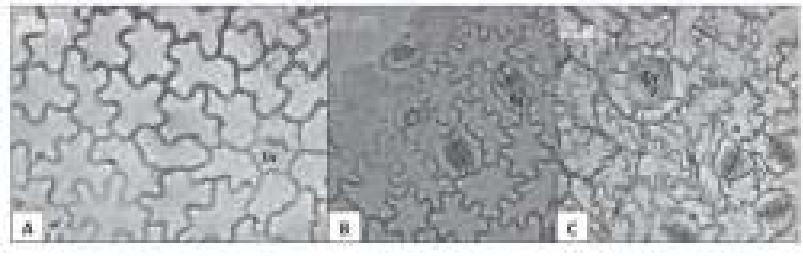

Figura 3. Folhas de E. uniflora em vista frontal. Face adaxial (A) e abaxial (B), Cv - cavidade secretora; Es - estômato.

Na região de internervura, em secções transversais, é possível notar os estômatos presentes ao mesmo nível das células epidérmicas (Figura 4A). Evidencia-se também epiderme unisseriada em ambas as faces, mesofilo dorsiventral, parênquima paliçádico unisseriado (Figura 4B). O parênquima lacunoso apresenta até nove camadas de células, idioblastos estão presentes organizados em série, contendo cristais do tipo drusas e prismáticos. Feixes vasculares de menor calibre são bicolaterais, circundados por uma bainha esclerenquimática (Figura 4C).

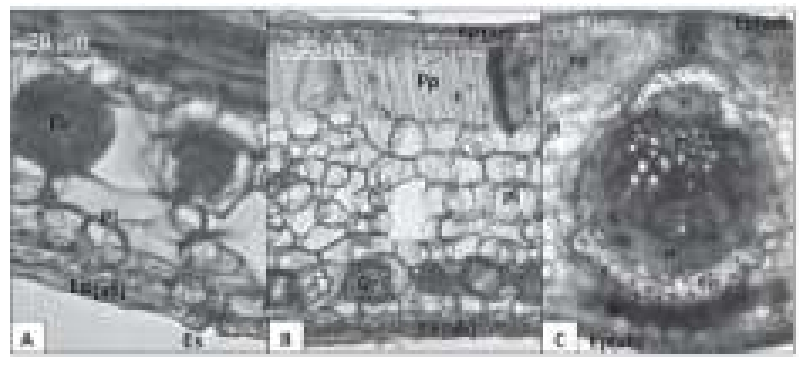

Figura 4. Região de internervura das folhas de E. uniflora em secção transversal. Detalhe do estômato em corte transversal (A), Mesofilo dorsiventral (B) e Feixe vascular de menor calibre (C).

Lorca, Amat e González ${ }^{15}$ apontaram a classificação do nível dos estômatos em relação às demais células epidérmicas como um dos fatores que permitiram a diferenciação entre E. uniflora e E. pyriformis. Segundo Rocha et al. ${ }^{16}$ a forma de organização dos cristais na família Myrtaceae pode apresentar importância diagnóstica.

No bordo foliar, em secções transversais (Figura 5), nota-se que o parênquima paliçádico é gradativamente substituído por células de colênquima, o que confere maior sustentabilidade à região do bordo, e uma espessa camada de cutícula recobre as células epidérmicas. Algumas estruturas secretoras e feixes vasculares podem ser evidenciados nessa 


\section{Artigo Geral 5}

região. Segundo Boeger e Wisniewski ${ }^{14}$ o espessamento da cutícula está relacionado com a maior retenção de água, proteção à luz solar e à ação de herbívoros.

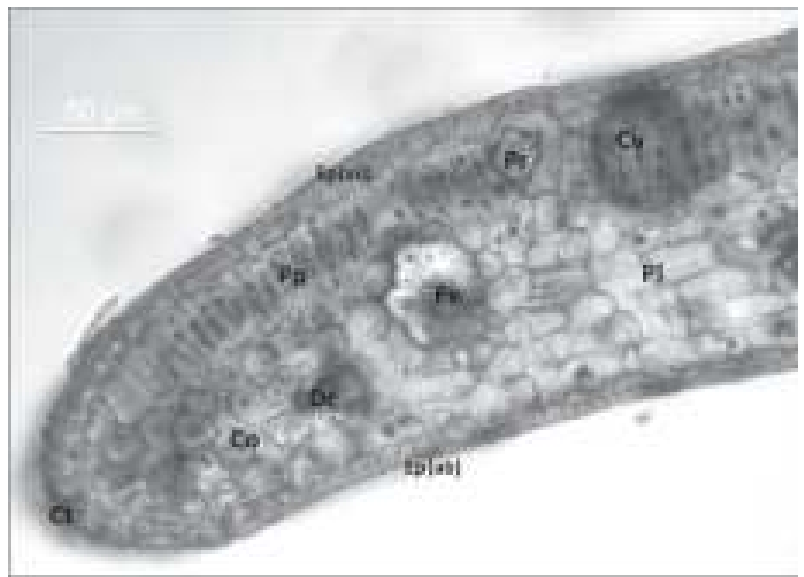

Figura 5. Região do bordo das folhas de E. uniflora em secção transversal. Legenda: $\mathrm{Ct}$ - cutícula; Co - colênquima; $\mathrm{Dr}$ - drusas; Pp - parênquima paliçádico; Fv - feixe vascular; $\mathrm{Pr}$ - cristal prismático; $\mathrm{Cv}$ - Cavidade secretora; $\mathrm{Pl}$ - parênquima lacunoso; Ep(ad) - epiderme adaxial; Ep(ab) - epiderme abaxial.

A nervura principal, em secção transversal (Figura 6) apresenta formato plano-convexo, confirmando a proeminência da nervura somente na face abaxial, a epiderme é uniestratificada. As células do parênquima paliçádico, assim como na região de bordo, gradativamente, dão lugar ao colênquima, este pode exibir idioblastos contendo cristais. O sistema vascular é bicolateral em forma de arco aberto e envolto por uma bainha esclerenquimática que confere maior rigidez a esta região ${ }^{14}$. Segundo Donato e Morretes ${ }^{17}$, as características, como estrutura dorsiventral e sistema vascular em formato de arco, são comuns para folhas adultas da família Myrtaceae.

O pecíolo apresenta forma côncavo-convexa (Figura 7A), com epiderme unisseriada em ambas as faces, seguida do tecido colenquimatoso que varia de duas a três camadas de células. A região de córtex é preenchida com até onze camadas de células parenquimáticas e é abundante em cristais dos tipos drusa e prismático em praticamente todas as camadas do tecido (Figura 7B), é possível também evidenciar cavidades secretoras. $\mathrm{O}$ feixe vascular tem forma de arco-aberto, com as extremidades voltadas para o centro, é bicolateral e apresenta cristais organizados em série no floema (Figura 7C).

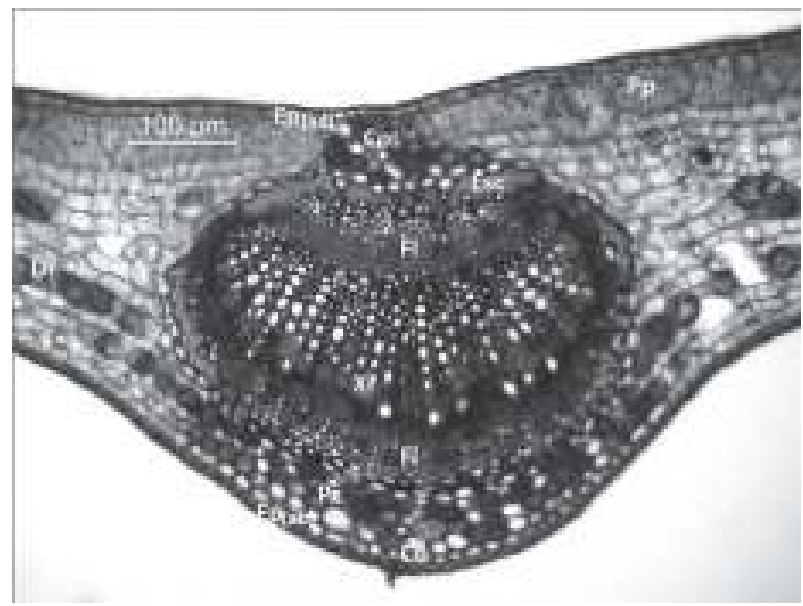

Figura 6. Região da nervura principal das folhas de E. uniflora em secção transversal. Legenda: Ep(ad) - epiderme adaxial; Ep(ab) epiderme abaxial; $\mathrm{Pp}$ - parênquima paliçádico; Co - colênquima; Esc - esclerênquima, Fl - floema; Pl - parênquima lacunoso; Dr - drusa; $\mathrm{Xi}$ - xilema; Pc - parênquima cortical.

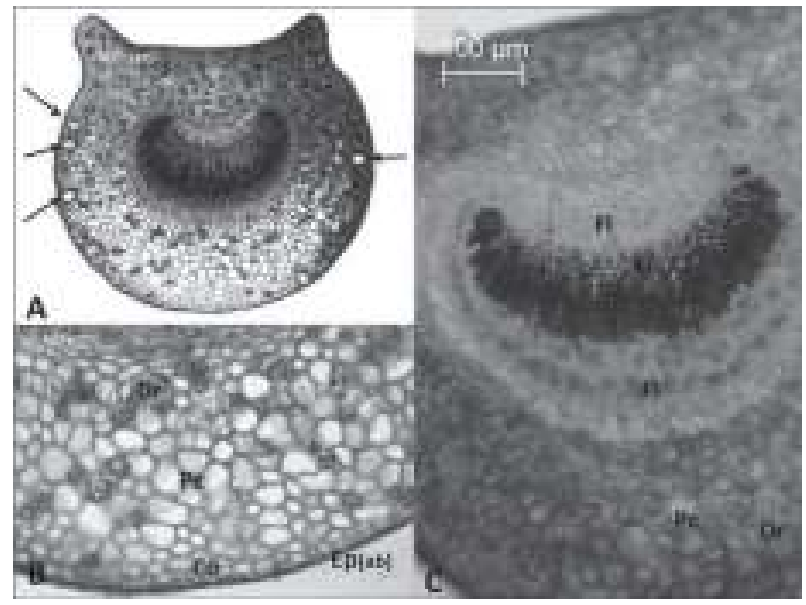

Figura 7. Região do pecíolo das folhas de E. uniflora em secção transversal. Vista geral do pecíolo (A), detalhe da região cortical (B) e detalhe do feixe vascular (C). Legenda: Ep(ab) - epiderme abaxial; Dr - drusa; Pc - parênquima cortical; Co - colênquima; Fl - floema; $\mathrm{Xi}$ - xilema. Setas indicam cavidades secretoras.

\section{Conclusão}

Os dados encontrados neste trabalho mostramse em conformidade com a monografia da espécie $E$. uniflora na Farmacopeia Brasileira $5^{\circ}$ edição, além de 
confirmarem muitas das características comuns à família Myrtaceae, tais como folhas hipoestomáticas, mesofilo dorsiventral e feixe vascular da nervura central em forma de arco. Também foi possível apontar estruturas que, quando associadas, apresentam valor de diagnose, como a presença dos estômatos ao mesmo nível das células epidérmicas, ausência de tricomas, ausência de hipoderme e disposição de cristais organizados em série na região de internervura e no floema do pecíolo.

\section{Referências}

1. Rotman, A.D. Boletin de la Sociedad Argentina de Botanica. 1995, 30, 63 .

2. Lorenzi, H.: Matos, F.J.A. Plantas Medicinais no Brasil: nativas e exóticas, 2a ed., Nova Odessa: São Paulo, 2008.

3. Simões, C.M.O.; Schenkel, E.P.; Gosmann, G.; Mello, J.C.P.; Mentz, L.A.; Petrovick, P.R. Farmacognosia da planta ao medicamento, 6a ed., Editora UFRGS: Porto Alegre, 2010.

4. Schapoval, E.E.S.; Silveira, S.M.; Alice, C.B.; Henriques, A.T. J. Ethnopharmacol. 1994, 31, 305.

5. Consolini, A.E.; Baldini, O.A.; Amant, A.G. J. Ethnopharmacol. 1999, 66, 33.

6. Momose, Y.; Araujo D.S.S.; Salguiro, F.; Caldas, J.G.; Felix, D.; Margis, R. Jpn Kokai Tokkyo Koho, 2000, 72, 770.

7. Oliveira, F.; Akisue, G.; Akisue, M. K. Farmacognosia. São Paulo: Atheneu, 1998.

8. Oliveira, F.; Akisue, G. Fundamentos de Farmacobotânica. 2. ed. São Paulo: Atheneu, 2003.

9. Kraus, J. E.; Arduin, M. Manual básico de métodos em morfologia vegetal. Universidade Rural: Rio de Janeiro, 1997.

10. Jorge, L.I.F.; Oliveira, F.; Kato, E.T.M.; Oliveira, I. Lecta. 1994, 2,103 .
11. Dias, C.N.; Rodrigues, K.A.F.; Resplandes, S.M.; Aguiar, L.R.; Amaral, F.M.M.; Moraes, D.F.C. Rev. Ciênc. Saúde. 2012, 14, 95.

12. Alves, E.S.; Tresmondi, F.; Longui, E.L. Acta bot. bras. 2008, 22, 241.

13. Donato, A.M.; Morretes, B.L. Rev. bras. Framacog. 2007, 17, 426.

14. Boeger, M.R.T.; Wisniewski, C. Rev. bras. bot. 2003, 26, 61.

15. Lorca, G.G.; Amat, A.G.; González, C. Acta Farm. Bonaerense. 1995, 14, 81

16. Rocha, L.D.; Preussier, K.H.; Pegorini, F.; Farias, V.; Maranho, L.T. Acta bot. brasilica. 2008, 22, 1114.

17. Donato, A.M.; Morretes, B.L. Rev. bra. Planta med. 2011, 13, 43.

\section{Paulo I. D. Assunção ${ }^{*}$, José R. de Paula² \& Joelma A. M. de Paula ${ }^{1}$}

${ }^{1}$ Programa de Pós-Graduação em Ciências Aplicadas a Produtos para Saúde. Universidade Estadual de Goiás. Anápolis, GO.

${ }^{2}$ Laboratório de Pesquisa de Produtos Naturais. Universidade Federal de Goiás. Goiânia, GO.

*E-mail: pauloisaac.da@gmail.com. 